\title{
Infantile spinal muscular atrophy (SMA) and multiple congenital bone fractures in sibs: a lethal new syndrome
}

\author{
Zvi Borochowitz, Benjamin Glick, Shraga Blazer
}

\begin{abstract}
Acute infantile spinal muscular atrophy (SMA type I, Werdnig-Hoffmann disease) has generally been accepted as an autosomal recessive disorder. However, several investigators have noted a slightly increased male to female ratio. We describe here a family with two affected male sibs who had a form of acute infantile SMA with congenital bone fractures, whose parents were first cousins. Pedigree analysis strongly suggested autosomal recessive inheritance, but $X$ linked recessive inheritance could not be ruled out. In view of the heterogeneity of the SMAs, and the distinct clinical features found in our patients, we suggest that their infantile SMA might well be a distinct entity. We suggest that SMA I with congenital contractures and bone fractures appears to be a recognisable disorder that can be distinguished from the more common classic form of SMA $I$.
\end{abstract}

The classification of the spinal muscular atrophies (SMAs) has been complex and controversial. ${ }^{12}$ To facilitate diagnosis and prognosis, several authors have classified progressive infantile spinal muscular atrophy into groups based on age of manifestation: an infantile type, or type I, and the late onset type, or type II. The manifestations are of graduated degree; therefore no classification scheme is entirely appropriate.

The Genetics Institute, Bnai-Zion Medical Centre, P 0 Box 4940, Haifa, Israel 31048.

Z Borochowitz

The Neonatal Department, Rambam Medical Centre, Haifa, Israel.

S Blazer

Technion-Faculty of Medicine, Haifa, Israel.

Z Borochowitz, S Blazer

Department of Pediatrics, Division of Child Neurology, Hadassah Mount-Scopus Medical Centre, The Hebrew University Faculty of Medicine, Jerusalem, Israel. B Glick

Correspondence to Dr Borochowitz.

Received for publication 7 August 1990

Revised version accepted for publication 24 October 1990.
Acute infantile SMA (SMA type I, WerdnigHoffmann disease) has generally been accepted as an autosomal recessive disorder. ${ }^{3}$ However, several investigators have noted a slightly increased male to female ratio. ${ }^{45}$

We describe here a family with two affected male sibs who had a form of acute infantile SMA with congenital bone fractures, born to first cousin parents (figure).

\section{Case reports}

PATIENT 1 (v.4)

A male infant was born to a healthy, young, consanguineous Bedouin-Moslem couple after 33 weeks' gestation. The pregnancy was complicated by polyhydramnios diagnosed by ultrasound and lack of fetal movements from the mid second trimester. This was their first pregnancy. At birth, he weighed $1950 \mathrm{~g}$ (-4 SD for age) and was noted to have profound hypotonia which necessitated artificial ventilation.

Physical examination in the neonatal period showed severe generalised oedema and length and head circumference on the 3rd centile. A left preauricular tag was noted, but there were no other dysmorphic features. Marked hypotonia, areflexia with severe proximal weakness, contractures of the knees and hips, and tongue fasciculations were also present.

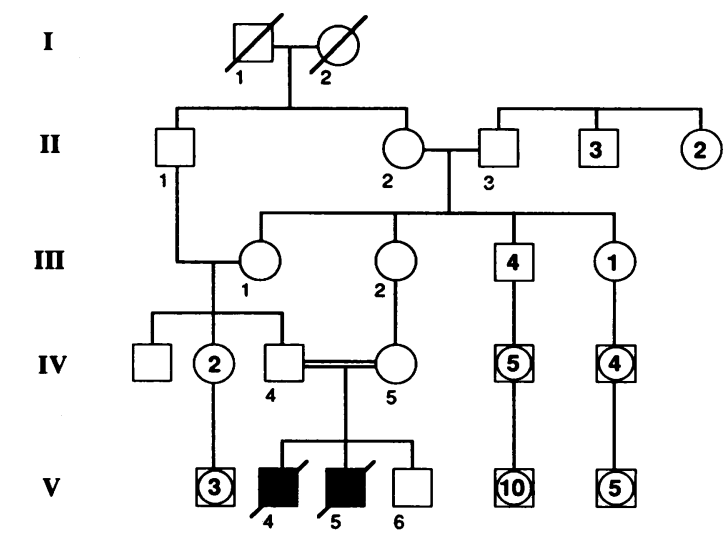

Family pedigree. 
Electromyography (EMG) showed changes consistent with a neurogenic disorder.

At the age of 15 days a spontaneous fracture of the right humerus was noted, and 10 days later another fracture of the left humerus was seen. General skeletal radiography showed normal ossification and modelling of the long bones. However, 11 thin looking ribs were noted on each side. His sclerae were not blue.

Skull $x$ ray showed normal ossification and configuration and Wormian bones were not found. No intracranial calcification or epiphyseal punctate ossification was noted. Metabolic screening, including blood for amino acids and gases, calcium, phosphorus, alkaline phosphatase, and vitamin D metabolites, were all within normal limits. TORCH antibody levels were within normal limits. CSF was normal. Muscle biopsy from the right quadriceps muscle was performed at 20 days (by BG). The histological findings on light microscopy showed pronounced fibre size variation. The majority of fibres showed advanced atrophy and among these were groups of hypertrophied fibres. The atrophic fibres were of both histochemical types, but type II predominance was obvious. On electron microscopic examination profound variation in fibre size was seen. In some of the atrophic fibres the myofibres were disorganised, reduced in number, or totally absent. These findings were consistent with acute infantile SMA type I. Neuromuscular problems persisted and the patient died at the age of 2 months. Necropsy was not performed.

PATIENT 2 (v.5)

This was the brother of patient 1 and was born at 37 weeks' gestation by caesarean section because of breech presentation. The pregnancy was complicated by polyhydramnios and lack of fetal movements. His birth weight was $3250 \mathrm{~g}$ and he was noted to have a weak cry and profound hypotonia which necessitated artifical ventilation. Physical examination at that time showed a hydropic baby with marked generalised pitting oedema. A fracture of his right humerus and contractures of both hips and knees were also noted. Severe hypotonia, areflexia, predominately proximal weakness, and tongue fasciculations were seen. His sclerae were not blue.

At 3 weeks of age fractures of the left humerus and right femur were noted. He was ventilated throughout his time in hospital with minimal movements or special treatment that might have caused iatrogenic bone fractures. Blood chemistry tests, including calcium, phosphorus, alkaline phosphatase, electrolytes, gases, and vitamin D metabolites, were all within normal limits. His karyotype was normal, $46, X Y$. General skeletal survey showed no osseous pathology except for 11 ribs which were somewhat thinner than expected, and the above mentioned long bone fractures. Skull $x$ ray was normal with no Wormian bones.

EMG done at 15 days showed low amplitude motor potentials in all muscles examined, compatible with a neurogenic disorder. Nerve conduction was normal for age.

Muscle biopsy (by GB) from the right quadriceps muscle confirmed the presence of a large quantity of atrophic fibres in between a few hypertrophic fibres. The atrophic fibres were mainly type II, consistent with the diagnosis of SMA type I. He died at 37 days of age and necropsy was not performed.

\section{Family history}

The parents are young first cousins, related through their mothers. They are of Bedouin-Moslem ancestry. Their third pregnancy resulted in a healthy male who is now a year old. No other persons in the family are known to be affected or have a history of neonatal deaths or bone fractures (figure).

\section{Discussion}

Clinical classification of the hereditary neuropathies has been based mainly on the distribution of muscle weakness, the progression of the disease, genetic factors, and associated features. The nosological delineation of the SMAs has been difficult. ${ }^{1-3}$ In his review on the nosology of the SMAs, Emery ${ }^{2}$ suggested a clinical genetic classification in which five categories were recognised on the basis of the clinical pattern: proximal SMA, distal SMA, juvenile progressive bulbar palsy, scapuloperoneal SMA, and facioscapulohumeral SMA. ${ }^{2}$ Proximal SMA was further divided into three subgroups based on the clinical severity: infantile, juvenile, and adult types. Furthermore, from a clinical point of view, two forms can readily be recognised: a severe infantile SMA, known also as Werdnig-Hoffmann disease (WH), and a mild SMA, known also as Wohlfart-Kugelberg-Welander disease. Between these two syndromes there is a group of cases of SMA with a wide range of disability. The clinical findings of the two male sibs reported here were similar. They showed congenital contractures, severe hypotonia and areflexia, and long bone fractures without major dysmorphic features. Decreased fetal movements and polyhydramnios were noted during pregnancy and death occurred within the first two months of life.

Muscle biopsy findings of both patients, as well as the EMG results, were interpreted as showing neurogenic atrophy and were classic examples of those seen in SMA I (Werdnig-Hoffmann syndrome). No necropsy was undertaken so that there was no direct proof of an anterior horn cell disease. Many features, however, supported a diagnosis of SMA, but the presence of congenital contractures and fractures 
suggests that their infantile SMA is a distinct entity. In view of the normal radiography of the long bones and skull $x$ ray without Wormian bones, osteogenesis imperfecta and other bone dysplasias could be ruled out.

Pedigree analysis of our patient's family strongly suggests autosomal recessive inheritance. The parents are first cousins, related through their mothers. However, $\mathrm{X}$ linked recessive inheritance can not be completely ruled out.

Congenital contractures (arthrogryposis) with infantile SMA was first reported by Brandt ${ }^{6}$ in 1947 and then by Frischknecht $e t a l^{7}$ in 1960 and Bargeton et $\mathrm{al}^{8}$ in 1961. An autosomal recessive mode of inheritance was suggested, as in cases of typical acute infantile SMA. ${ }^{3910}$ Bone fractures were not part of this entity. Becker ${ }^{9}$ suggested an allelic model for SMA I, where the $a^{\prime \prime} a(+)$ genotype would lead to this phenotype, and Bouwsna and Leschot ${ }^{10}$ suggested an extended allelic hypothesis, as different types of SMA were present in six of the seven pedigrees reported.

Several cases have been previously reported with congenital contractures, hypotonia, possible SMA, and apparent $\mathrm{X}$ linked recessive inheritance. A male infant with features consistent with $\mathrm{X}$ linked arthrogryposis was reported by Stoeber. ${ }^{11} \mathrm{He}$ had hypotonia and contractures at birth, kyphoscoliosis, and pectus excavatum. Bone fractures were not present. No muscle biopsy or necropsy findings were available.

Banker et al $^{12}$ reported two brothers with congenital contractures. Case 1 was a breech birth and a femur was fractured at birth. Severe mid-dorsal kyphoscoliosis and bilateral calcaneovalgus deformity were also present. Muscle biopsy was reported to be abnormal with fibre loss and variability of fibre diameter on cross section. He died at $51 / 2$ months from respiratory failure. No other bone fractures were diagnosed after birth. His brother, case 2, was also a breech presentation with a resulting fracture of the femur. He died at 1 1 $1 \frac{2}{2}$ hours and had muscle findings similar to his brother. The bone fractures noted in these two cases were most probably attributable to delivery. Furthermore, the severe congenital kyphoscoliosis found in both was quite distinct, and thus different from the clinical presentation of our patients.

In a brief case report by Ramakumar and Sood, ${ }^{13}$ a male infant was reported who died on the fourth day of life with congenital contractures and a fracture of the left humerus. The facial features were reportedly similar to those of the patients described by Banker $e t$ al. ${ }^{12}$ However, kyphoscoliosis was not present and hypotonia was only suggested by the receding mandible and bifid uvula as the basis for the PierreRobin syndrome. Necropsy was not performed. This case has similarities to ours, but SMA was not diagnosed. A fourth published report with some similarities to our family was reported by Short ${ }^{14}$ as a 'congenital muscular dystrophy'. The male proband was hypotonic with generalised joint stiffness and muscle histopathology which was interpreted as being consistent with a spinomuscular atrophy. He died at 6 months. No bone fractures were ever noted.

In 1982, Hall et $a l^{15}$ reported three distinct types of $\mathrm{X}$ linked arthrogryposis seen in six families. In the first type, a severe, lethal, intrauterine SMA was found in addition to congenital arthrogryposis and kyphoscoliosis. In the second type, a moderately severe, non-lethal myopathy was suggested as the aetiology for the contractures. In the third type, a resolving type, the contractures ameliorated with time. A connective tissue disorder or misplaced tendons were suggested as the cause of contractures in these patients. In all three types, bone fractures were not present.

Historically, Werdnig-Hoffmann disease has been distinguished clinically from arthrogryposis by hypotonia without contractures at birth. However, it had been indicated by Pearn and Wilson ${ }^{16}$ that WH disease can occur with contractures. Furthermore, it is probable that WH-like patients with congenital contractures are not seen in the same families as classic WH disease.

In their report, Hall et al ${ }^{15}$ emphasised that forms of congenital (intrauterine) spinal muscular atrophy/ dystrophy such as Werdnig-Hoffmann disease might be confused with the conditions seen in their patients grouped as the severe lethal type I. It has therefore been agreed that the SMAs represent a heterogeneous group.

The cases reported by Greenberg et al ${ }^{17}$ with an apparent $\mathrm{X}$ linked infantile SMA, congenital contractures, multiple bone fractures, and neonatal death seem clinically to be most similar to our patients' disorder, and we agree with Greenberg et al $^{17}$ that their cases do represent a distinct entity of lethal infantile SMA with congenital contractures and multiple bone fractures. This entity is quite different from the type $\mathrm{I}$, severe, lethal, $\mathrm{X}$ linked arthrogryposis which has been previously reported. ${ }^{11-15}$

In the family reported here, consanguinity was present and a diagnosis of SMA was made: therefore, autosomal recessive inheritance might well be sug gested. In view of the heterogeneity of the SMAs, and the distinct clinical features found in our patients (the presence of congenital contractures and, even more specifically, bone fractures), we suggest that their infantile SMA might well be a distinct entity, distinguishable from the more common classic form of SMA $I .^{3}$ However, further reports and family studies are needed to elucidate the exact mode of inheritance.

At present, families who are at risk of being carriers of this disorder should be counselled about the possibility of both autosomal and $\mathrm{X}$ linked recessive inheritance. The option of ultrasonographic midtrimester prenatal diagnosis should also be suggested, 
as fetal contractures and bone fractures might well be detected.

1 Byers RK, Banker BQ. Infantile muscular atrophy. Arch Neurol 1961;5:140-2.

2 Emery AEH. The nosology of the spinal muscular atrophies. 7 Med Genet 1971;8:481-95.

3 McKusick VA. Mendelian inheritance in man: catalog of autosomal dominant, autosomal recessive and $X$-linked phenotypes. 7th ed. Baltimore: Johns Hopkins University Press, 1989.

4 Emery AEH, Davie AM, Holloway S, et al. International collaboration study of the spinal muscular atrophies. II. Analysis of genetic data. $\mathcal{F}$ Neurol Sci 1976;30:375-84.

5 Pearn JA. Genetic studies of acute infantile spinal muscular atrophy (SMA type I): an analysis of sex ratio, segregation ratios, and sex influence. 7 Med Genet 1978;15:414-7.

6 Brandt S. A case of arthrogryposis multiplex congenita anatomically appearing as a foetal spinal muscular atrophy. Arch Paediatr Scand 1947;34:365-81.

7 Frischknecht W, Branchi L, Pillerie G. Familiare arthrogryposis multiplex congenita: neuro-arthro-myodysplasia congenital. Helv Paediatr Acta 1960;15:203-9.
8 Bargeton E, Nezelof C, Guran P, et al. Etude anatomique d'un cas d'arthrogrypose multiple congenitale et familiale. Rev Neurol 1961;104:479-89.

9 Becker PE. Atrophie musculorum spinalis pseudomyopathica. Hereditare neurogene proximale Amyotrophie von Kugelberg und Velander. $Z$ Mench Vererb Konstit Lehre 1964;37:193-220.

10 Bouwsna G, Leschot NJ. Unusual pedigree patterns in seven families with SMA: further evidence for the allelic model hypothesis. Clin Genet 1986;30:145-9.

11 Stoeber E. Kleine Mitteilinung: Uber atonisch-sklerotisch muskeldystrophie (Typ Ullrich). Z Kinderheilkd 1938;60: $279-84$.

12 Banker BQ, Victor M, Adams RD. Arthrogryposis multiplex. Brain 1957;80:319-34.

13 Ramakumar L, Sood SC. Arthrogryposis multiplex congenita with Pierre Robin syndrome. Ind f Pediatr 1961;28:172-3.

14 Short JK. Congenital muscular dystrophy. Neurology 1963;13: 526-30.

15 Hall JG, Reed SD, Scott CI, Rogers KL, Jones KL, Camarano A. Three distinct types of $\mathrm{X}$-linked arthrogryposis seen in six families. Clin Genet 1982;21:81-97.

16 Pearn JH, Wilson J. Acute Werdnig-Hoffmann's disease. Arch Dis Child 1973;48:425-30.

17 Greenberg F, Fenolio KR, Hejtmanick JF, et al. X-linked infantile spinal atrophy. Am $\mathcal{J}$ Dis Child 1988;142:217-9. 